\title{
REPUBLICANAS EN PIE DE PAZ. LA SUSTITUCIÓN DE LAS ARMAS POR LA JUSTICIA, EL ARBITRAJE Y EL DERECHO (1868-1899)*
}

\begin{abstract}
$\mathrm{M}^{\mathrm{a}}$ Dolores Ramos
«El ramo de oliva podrá ser llevado muy pronto al campamento de los soldados que luchan por la integridad de la patria; pero ¿cuánto tiempo habrá que esperar a que sea traído entre nosotros, los que luchamos por el triunfo de la justicia y el derecho?»
\end{abstract}

Amalia Carvia

\section{Preliminares}

Uno de los aspectos más desconocidos de la cultura política republicana es el movimiento antimilitarista, a favor de los tribunales de arbitraje y el desarme promovido por las asociaciones feministas librepensadoras. La finalidad de este artículo es analizar estas aportaciones en una etapa marcada por el auge del imperialismo, los nacionalismos, la carrera armamentística y las paradojas de la modernidad. Una etapa que en términos políticos supuso para España el triunfo de la «Gloriosa», el brevísimo y agitado ensayo de la Primera República y la Restauración monárquica, régimen que antes de que concluyera el siglo facilitaría la alternancia de conservadores y liberales en el poder, aprobaría el sufragio universal masculino y conocería su primera gran crisis definida, entre otros aspectos, por el cierre -«sin honra»- de la guerra hispanonorteamericana, las plurales interpretaciones del concepto «República» y los cambios de estrategias de sus mentores políticos. En este sentido, federales, centralistas, blasquistas, unionistas, germinalistas y lerrouxistas mantuvieron un pulso en el que participaron -ubicadas en los márgenes, pero con voz

\footnotetext{
* Trabajo realizado en el marco del Proyecto I+D+I número 149/05.
} 
propia- las «afiliadas» y seguidoras que se habían negado a ser "portaestandartes», «floreros», objetos de adorno en los mítines, meriendas electorales y conmemoraciones, denunciando lo que ellas calificaban de «tibieza republicana». En ese marco defendieron su identidad política y su autonomía personal, declarándose «republicanas de nadie», «republicanas de la República», porque ésta no podía ser «monopolizada por un hombre, ni por unos cuantos hombres, sino elevada por la invencible fuerza popular ${ }^{1}$.

Esta confrontación política entre los sexos, no siempre visible debido al comportamiento paternalista de los varones republicanos y la aceptación parcial de los papeles de género por parte de las mujeres republicanas, se produjo en unos momentos en los que se discutía qué alcance y límites debería adquirir la «cuestión femenina» y cómo reforzar los rasgos de una laicidad, predominantemente masculina, dirigida a establecer pautas de sociabilidad secularizadas -ámbito donde las mujeres tenían «algo» que decir y mucho que hacer-, fuera de la moral y las prácticas de vida de las religiones positivas. No iba mucho más allá el horizonte previsto para las mujeres. No obstante, la proximidad del nuevo siglo, con sus expectativas de cambio y sus transgresiones políticas, éticas y estéticas, potenció en las filas femeninas discursos y actos de autonomía, «deslealtad»o «rebeldía» que revelaron la importancia de un espacio en construcción pleno de posibilidades futuras. Estaba en juego la reformulación de la ciudadanía, la laicidad y la feminidad en el ámbito de las culturas políticas de izquierdas, la utilización de redes nacionales y transnacionales para establecer renovados compromisos a favor de la paz, el antimilitarismo, la libre conciencia y el progreso de las libertades².

En este sentido las movilizaciones pacifistas no pueden entenderse sin el concurso de las mujeres que trabajaron en los partidos políticos, asociaciones feministas, entidades librepensadoras, logias masónicas, círculos espiritistas y ramas teosóficas, aportando reflexiones -elementos discursivos- y producciones -elementos sociopolíticos- que contribuyeron a transformar las sociedades de amigos de la paz surgidas al calor de la «revolución de los pueblos», los ideales utópicos y las formulaciones demo-liberales a mediados del siglo XIX. En torno a 1900 se cimentará una cultura pacifista cada vez más feminizada e imbricada en la sociedad civil, lejos de la visión oficial que tenían los Estados y sus portavoces diplomáticos, delegados políticos, militares y juristas sobre la política exterior y las relaciones internacionales. Las «modernas» constructoras de la paz no sólo estaban dispuestas a ejercer el papel que

1. La Conciencia Libre. Segunda Época. Año II. Málaga, nº 11, 1-II-1906.

2. La Conciencia Libre, Primera Época. Año VI. Málaga, nº 213, 7-IX-1901. 
históricamente habían jugado como mediadoras y reguladoras de conflictos en la vida cotidiana sino que politizaron sus propuestas y experiencias, negaron cualquier forma de autoridad moral a las guerras y reclamaron organizadamente a los gobiernos soluciones preventivas, negociaciones y prácticas de arbitraje ${ }^{3}$. De acuerdo con el discurso antimilitarista tolstoiano que priorizaba el amor a la humanidad por encima del amor a la Patria y el «mandato» de los papeles de género -dar y conservar la vida-, las mujeres racionalistas ligaron la cultura de la paz con sus experiencias como madres biológicas y sociales y con sus propios proyectos de emancipación sexual, se movilizaron contra las guerras, el mantenimiento de las quintas, la redención en metálico, los consumos, el estado de las cárceles, abogaron por la supresión de la tortura y la pena de muerte, se comprometieron en la defensa del caso Dreyfus y la revisión del proceso de Montjuich, e impulsaron, en fin, la Primera Conferencia de la Paz celebrada en La Haya en 1899.

Es preciso señalar que en esos años la cultura de la paz estaba segmentada por una pluralidad de discursos, prácticas y movimientos sociales no siempre convergentes, pero sí entrecruzados: el pacifismo liberal de base pequeñoburguesa, divulgado por entidades republicanas y librepensadoras enraizadas en la sociedad civil, a las que prestaron su concurso numerosas líderes: Bertha von Suttner, Lenore Selenka, María Pognon, Cammille Flammarion, Belén Sárraga, Julia Álvarez, Amalia Carvia, Carmen Ferrero, Ángeles López de Ayala, entre otras; el pacifismo internacionalista de base obrera surgido en ámbitos anarquistas y socialistas con un sentido antimilitarista y antiimperialista, surcado de voces femeninas en la prensa y los Congresos Internacionales: Emma Goldman, Teresa Claramunt, Teresa Mañé, Clara Zetkin, Rosa Luxemburgo, Alexandra Kollontai. Tanto en uno como en otro caso las mujeres acabaron rompiendo amarras en determinadas coyunturas, contrariaron las consignas establecidas y constituyeron un espacio pacifista propio, como ocurrió entre las federales españolas con motivo de la celebración de la Primera Conferencia de la Haya en 1899 o entre las socialistas europeas que, ignorando los postulados de La Union Sacrée, convocaron el Congreso Internacional de Mujeres por la Paz en 1915.

En gran medida, estos hechos no han merecido la atención de los analistas del derecho, las relaciones internacionales y la historia diplomática, pero están siendo estudiados desde la óptica de los estudios de género y las modernas investigaciones por la $\mathrm{paz}^{4}$. En las páginas que siguen me centraré en las

3. La Conciencia Libre, Segunda Época Año II. Málaga, n 34, 21-VI-1906.

4. MARTíneZ LÓPEZ, Cándida (coord.), Mujeres, paz y regulación de conflictos (Monográfico), Arenal. Revista de Historia de las mujeres, vol. 5, nº 2 (1998), pp. 239-337; AGUADO, 
pautas de feminización del pacifismo liberal durante el siglo XIX prestando atención al activismo desplegado por las españolas durante la Primera Conferencia de La Haya. Estas manifestaciones coincidieron en nuestro país con la firma del Tratado de París, los efectos materiales y morales de la crisis de 1898 y el cuestionamiento de la política exterior, o más bien las críticas por su inexistencia. En ese contexto las pacifistas europeas plantearon estrategias comunes y movilizaciones al grito de «guerra a la guerra ${ }^{5}$.

\section{El «apostolado» de las mujeres por la paz en la segunda mitad del siglo XIX}

«La paz, idea tan dulce y conciliadora, suele tener dolores y amarguras, porque se hace como la guerra, en virtud de la voluntad del más fuerte»

Concepción Arenal

En 1867 se celebró en Ginebra el Congreso de la Paz que propició la creación de la Liga por la Paz y la Libertad, fundada por núcleos de emigrados políticos -mayoritariamente refugiados de 1848- en torno a Julio Barni y Giuseppe Garibaldi. No fue el primer congreso celebrado con la finalidad de impulsar la abolición de las guerras, iniciativa que contaba con una larga tradición inaugurada en Londres (1843), Bruselas (1848) y París (1849), pero sí puede considerarse pionero a la hora de dictaminar la necesidad de establecer una Federación Republicana de Pueblos Libres basada en la firma de tratados de amistad y arbitraje permanentes entre países con intereses, sentimientos y formas culturales afines ${ }^{6}$. El objetivo último era la formación de los Estados Unidos de Europa, entidad que debía regular las relaciones internacionales

Anna (ed.), Mujeres, regulación de conflictos sociales y cultura de la paz, Valencia, 1999; BAllesteros, Rosa, «Sara Beirao. Conferencia pronunciada en la sede del Consejo Nacional de Mujeres portuguesas en un acto conmemorativo por la paz», Arenal. Revista de Historia de las Mujeres, vol. 8, $\mathrm{n}^{\circ} 1$ (2001), pp. 179-192. NASH, Mary y TAVERA, Susana (eds.), Las mujeres y las guerras, Barcelona, 2003; Mirón PÉREZ, Ma Dolores (dir.), Las mujeres y la paz: génesis y evolución de conceptualizaciones, símbolos y prácticas, Madrid, 2004; NASH, Mary, Mujeres en el mundo. Historia, retos y movimientos, Madrid, 2004, pp. 147-157; SANFELIU, Luz, Republicanas. Identidades de género en el blasquismo, Valencia, 2004, pp. 119-128; EsPINAR RUíz, Eva y Nos AldAs, Eloísa (coords.), Género, conflicto y construcción de la paz. Reflexiones y propuestas (Monográfico), Feminismo/s, nº 9 (2007). LÓPEZ, Mario, «La sociedad civil por la paz», en MUÑOz, Francisco y LóPEZ, Mario (coords.), Historia de la Paz. Tiempos, espacios y actores, Granada, 2000, pp. 291-357.

5. La Conciencia Libre. Segunda Época. Año II. Málaga, nº 11, 10-II-1906.

6. Magalhaes Lima, Sebastiao, Episodios da minha vida. Memorias documentadas. Viajens, homens e factos. Tomo II. Lisboa, s.a., pp. 74-75. 
según los «sagrados» principios del liberalismo político: Libertad, Igualdad y Fraternidad ${ }^{7}$. Para difundir este compromiso se creó la revista Etats Unis d'Europe, editada en francés y alemán, cuyo ideario marcó las pautas políticas desarrolladas por el librepensamiento europeo a partir de entonces: una República laicista-pacifista que eliminara los ejércitos profesionales, apostara por la educación mixta y gratuita, acortara las diferencias entre las clases sociales y los sexos, propagara la fe en el progreso y la destrucción de sus principales enemigos: el clero católico y el militarismo prusiano.

Una de las grandes novedades de la revista fue la incorporación de un grupo de redactoras que escribieron sobre educación, derechos femeninos y laicismo. Destacaba entre ellas la pionera del feminismo suizo, Marie GoeggPouchoulin (1826-1899), autodidacta formada en los círculos radicales de la emigración política centroeuropea, casada con el exiliado socialista alemán Amand Goegg, madre de tres hijos y fundadora de la Asociación Internacional de Mujeres (1868), uno de los primeros núcleos organizados del pacifismo femenino en Europa. Marie Goegg-Pouchoulin creó una red basada en contactos epistolares y personales, así como un programa de actividades que incluía la constitución de comités que sostuvieran moral y financieramente a la Liga por la Paz y la Libertad, la fundación de círculos de lectura y la organización de conferencias y debates. Este espacio sociocultural debía librar a las mujeres de su aislamiento, crear lazos de solidaridad y reforzar las identidades femeninas:

«Comment donc entrependre la croisade que nous reconnaisons être nécessaire? En nous disant que des forces divisées n'arrivent à rien, tandis que reúnies elles peuvent transporter des montagnes. Courage donc, fondatrices de comités, amies dévouées de tout ce qui est noble, ne vous rebutez pas devant les dificultés de l'entreprise et l'exiguité de vos ressources. Ne croyez pas, comme quelques-uns le diront peut-être, que nous détournerons ainsi les femmes de leurs devoirs domestiques et que le temps passé au cercle serait mieux employé dans leurs maisons. Ceux qui tiendront ce langage, son ceux que ne comprennent rien aux aspirations actuelles de la société» ${ }^{8}$.

La Asociación Internacional de Mujeres trabajó por la erradicación de los conflictos bélicos junto con la Liga por la Paz y la Libertad, entidad que instó a sus afiliadas a tomar parte en sus deliberaciones, equiparándolas por primera vez a los hombres a efectos de votaciones y resoluciones?

7. Ibidem, pp. 80-82.

8. Woodtli, Susanna, Du féminisme à l'egalité politique. Un siècle de luttes en Suisse, 18681971, Lausanne, 1977, p. 17.

9. Pierson, Ruth R. (ed.), Women and Peace. Theoretical, historical and practical perspectives, London-New York-Sidney, 1987, pp. 54-55. 
Las españolas, aunque no llegaron a afiliarse a estas sociedades integradas mayoritariamente por suizas, francesas, italianas y alemanas, plantearon acciones contra las quintas, la guerra y los consumos poniendo en práctica una doble estrategia de politización de los espacios públicos y privados. La creación en Madrid de la Asociación de Mujeres Republicanas el año 1869, dirigida por Carmen Munté, la apertura del Club Republicano de Mujeres Mariana Pineda en Cádiz, impulsado por Guillermina Rojas, y la fundación del Club de Mujeres de Alicante, presidido por Rita Bataller, muestran una secuencia de experiencias muy similares a las registradas en Zaragoza, bajo el liderazgo de Modesta Periu, Valencia, Valladolid y Sevilla. Radicalismo, federalismo, internacionalismo, emancipismo y pacifismo integran las coordenadas del modelo de República defendido por estas activistas que inscribieron en su proyecto político la abolición del servicio militar obligatorio por considerar que era una «odiosa contribución de sangre» especialmente frustrante para las madres, esposas y hermanas de los soldados ${ }^{10}$.

No había terminado la década de los setenta cuando Concepción Arenal publicó su Ensayo sobre el Derecho de Gentes ${ }^{11}$, cuyo capítulo octavo está dedicado al estudio pormenorizado de la guerra, de la que ofrece algunas definiciones a cargo de diferentes estudiosos, no dudando en incluir la suya: «el empleo de todos los medios violentos que consideran necesarios o convenientes dos Estados o colectividades poderosos que luchan entre sí para conseguir un fin que puede o no ser justo». La penalista y filántropa española se ocupa de las tipologías de los conflictos, sus leyes, treguas, secuelas y armisticios, y también analiza las debilidades de la paz. En este tema, como en otros muchos, fue una adelantada y cultivó los contactos con las reformadoras europeas, algunas vinculadas a las escuelas fourieristas, como Isabelle Bogelot, Zoe Gatti de Gamond y Josefina Butler ${ }^{12}$.

Se producía así la respuesta del feminismo a la expansión del imperialismo internacional y el estallido de conflictos bélicos como el de los boers y el

10. ESPIGADO, Gloria, «Mujeres «radicales»: utópicas, republicanas e internacionalistas en España (1848-1878)», en RAmOS, Mª Dolores (ed.), República y republicanas en España (Monográfico), Ayer, no 60 (2005), pp. 34-41; «Experiencia e identidad de una internacionalista: trazos biográficos de Guillermina Rojas Orgis», Arenal. Revista de Historia de las Mujeres, vol. 12, nº 2 (2005), pp. 255-280.

11. Arenal, Concepción, Ensayo sobre el Derecho de Gentes, Madrid, 1879. Reedición en Biblioteca Virtual Miguel de Cervantes (Alicante, 1999).

12. LACALZADA, $\mathrm{M}^{\mathrm{a}}$ José, La otra mitad del género humano. La panorámica vista por Concepción Arenal (1820-1893), Málaga, 1994, pp. 178-189; RAMOS, Mª Dolores, «Isabel II y las mujeres isabelinas en el juego de poderes del liberalismo», en PÉrEZ GARZÓN, Juan Sisinio, Isabel II. Los espejos de la reina, Madrid, 2004, pp. 141-156 y WOODTLI, Susanna, Du féminisme à l'egalité politique..., p. 12. 
franco-prusiano, que llevó a las mujeres a reivindicar la paz pero también, paradójicamente, a tomar las armas para defenderse a sí mismas y a sus familias. En la Comuna de París las revolucionarias patrullaron las calles, levantaron barricadas, empuñaron fusiles y fueron ejecutadas en los muros de la ciudad. Conocemos el apellido de algunas: Duvigneau, Gentil, Blin, Deletras, Langlois, Lemel; pero será Louise Michel (1839-1905) la que destaque entre todas. Vestida de negro o con uniforme de la Guardia Federal, la «gran ciudadana» dio muestras en su correspondencia con Víctor Hugo de un arrojo que como mujer no debía manifestar por ser «patrimonio cultural» de los hombres: «Francia será grande porque acaba de encontrar su alma ahora. Somos felices. No nos importa la muerte, sabremos vencer. Somos valientes» ${ }^{13}$. A partir de 1880, tras regresar de su destierro en Nueva Caledonia, el antimilitarismo revolucionario de Louise Michel se definiría, igual que el de los anarquistas Émile Pouget y Salvador Faure, como un canto de amor a la humanidad y un instrumento de litigio permanente contra el Poder ${ }^{14}$.

No tiene nada de extraño, ya que la construcción del movimiento pacifista se asentó a finales del siglo XIX en tres pilares: la flexibilización de fronteras y el establecimiento de mecanismos de arbitraje; la transformación de las conciencias mediante una revolución interior que se fundamentara en la práctica de la solidaridad y propagara el concepto de «Patria Universal» ${ }^{15}$; el rechazo del militarismo en todas sus formas políticas, institucionales e ideológicas, así como la crítica de los principios económicos, nacionalistas y religiosos que lo sustentaban, entre los que sobresalía la disciplina «ciega, mecánica y pasiva» que propicia jerarquías y privilegios y genera «un falso patriotismo de consecuencias deplorables desde el punto de vista moral y material $»^{16}$. En los tres frentes se integraron las mujeres que fundaron entidades antimilitaristas y ligas a favor del arbitraje ${ }^{17}$.

Pero si la pacifista Bertha von Suttner ${ }^{18}$ (1843-1914) mereció el honor de figurar, rodeada de eminentes varones, en el cuadro de Henri Danger Los

13. Michel, Louise, Lettres à Victor Hugo. 1850-1879. Choisies, préfacees et annotées par Xavière Gautier, Paris, 2005, p. 48 y Mémoires [Completes], Bruxelles, 2005, p. 573.

14. GaUthIER, Xavière, La vierge rouge. Biographie de Louise Michel, Paris, 1999.

15. La Luz del Porvenir, 4-X-1888.

16. FuRnEMONT, Leon, Le militarisme, voilá l'ennemi, Bruxelles, 1898, pp. 6-15.

17. Entre otras, la Unión Internacional de Mujeres, establecida por Eugènie Potonié-Pierre en 1895, la Liga de Mujeres por el Desarme, creada el año 1896 bajo la dirección de Gabrielle Wiesniewska en Francia y Johanna Wasklewcz-Van Schilfgaarde en Holanda, y las diferentes Asambleas nacionales organizadas con motivo de la Primera Conferencia de Paz de La Haya.

18. Compartió militancia con el diputado francés Fréderic Passy, fundador de la Sociedad Francesa de Amigos de la Paz y primer Premio Nobel de la Paz en 1901. Así mismo, 
apóstoles de la Libertad, expuesto en el Salón de París de 1890, la ausencia en el lienzo de otras antimilitaristas indica que la unión simbólica entre las mujeres y la paz no formaba parte del ámbito de la política, hecho que representó «una fuente de resistencia a la universalización del valor de la paz, cuya asociación con lo femenino [equivalía] en la práctica a una devaluación ${ }^{19}$. Suttner elaboró un discurso que enlazaba con el de Marie Goegg-Pouchoulin, acentuó la necesidad de materializar la federación política y previó la llegada de luchas épicas, «indignas de nuestra civilización», entre los pueblos latinos, los eslavos y los germanos si no se ponía en marcha de manera gradual el proceso federativo y la solidaridad internacional ${ }^{20}$.

Obviamente, no hablo de un punto de llegada, ni siquiera de un punto de partida. En mayor o menor medida, la idea de que las mujeres son por naturaleza «pacifistas» y los hombres están abocados a la guerra «con toda la fuerza de su sexo ${ }^{21}$, ha sido aplicada a las sociedades antiguas, medievales y del Antiguo Régimen, donde las atribuciones de Eirene y Pax, las opciones representadas por Antígona e Ismene, y las prácticas de mediación y regulación de los conflictos agrupadas bajo el lema Semper pacis amica, han tenido continuidad en las estrategias discursivas, el movimiento asociativo y las acciones de protesta desarrolladas en siglos posteriores ${ }^{22}$. Desde la campaña lanzada por la Sociedad Autónoma de Mujeres de Barcelona en 1889 para rechazar la carrera armamentística, la guerra y los ejércitos permanentes, con el respaldo de la masonería catalana y española, a las acciones de las redactoras del diario La Fronde, lideradas por su directora Marguerite Durand, que consideraba a las mujeres un «factor de paz». La fundación en 1899 de la Société d'arbitrage

entró en contacto con la Asociación Internacional de Arbitraje y de la Paz de Londres y participó en la fundación de la Asociación Austriaca por la Paz, de la que sería presidenta, y la Oficina Internacional de la Paz, con sede en Berna. Este compromiso ocupó gran parte de su vida. Ver PORQUERES, Bea, Tres creadores contra les guerres. Bertha von Suttner (1843-1914), Kathe Koowitz (1867-1945), Marga Ximenez (1950), Barcelona, 2005, pp. 56-57.

19. MagAllón Portoles, Carmen, «De la reclamación de la paz a la participación en las negociaciones. El feminismo pacifista», en ESPINAR RUIZ, Eva y NOS AldÁs, Eloísa (coords.), Género, conflicto y construcción de la paz..., p. 21.

20. « Bertha de Suttner », en MAgalHAES Lima, Sebastiao, Episodios da minha vida..., p. 93.

21. Ballesteros, Rosa, «La Paz en el discurso feminista portugués», en Aguado, Anna (ed.), Mujeres, regulación de conflictos..., p. 205.

22. MARTínEZ LÓPEZ, Cándida, «Conceptualización y prácticas pacíficas femeninas en las sociedades antiguas» y MUÑOZ FERNÁNDEZ, Ángela, «Semper pacis amica. Mediación y práctica política (siglos VI-XIV)», Arenal. Revista de Historia de las Mujeres vol. 5, n 2 (1998), pp. 239-261 y 263-276 respectivamente e IRIARTE, Ana, «Antígona e Ismene: dos opciones femeninas ante el poder», en AGUADO, Anna (ed.), Mujeres, regulación de conflictos..., pp. 19-27. 
entre les nations, en la que militaba Marie Pognon con otras feministas, y la Société La Paix et le Desarment par les Femmes, creada ese mismo año por la librepensadora Sylvie-Cammille Flammarion, suponen un salto cualitativo en la politización del pacifismo femenino, que a partir de esos momentos construirá organizaciones específicas, establecerá tácticas comunes y acciones colectivas con la idea de resolver los conflictos internacionales mediante el arbitraje y el concurso de las mujeres ${ }^{23}$.

\section{Fin de siglo. Protagonistas españolas del feminismo pacifista de base republicana y librepensadora}

«La falange femenina no marcha batiendo tambor guerrero; va despacio, con el lento y tranquilo andar del que tiene que ir llamando de puerta en puerta (...) Aunque en la prensa no se refleje la importancia de este movimiento feminista; aunque la indiferencia proverbial de nuestra España parezca ser la que responda a nuestra voz, no hay duda que el pensamiento de la mujer de hoy flota más alto y recoge anhelante cuanto le habla de libertad para sus sentimientos y de libertad para sus acciones. Con esto hay bastante para levantar una enseña y pedir libre paso ${ }^{24}$.

Quien así hablaba, la gaditana Amalia Carvia, sabía que el avance del feminismo laicista había sido propiciado por un amplio movimiento asociativo que ella y otras republicanas habían contribuido a poner en pie a partir de 1889. No es mi intención reproducir esa historia ${ }^{25}$, sino ubicar el pacifismo postu-

23. La Fronde, 1-I-1899. Sylvie-Cammille Flammarion, de soltera Renaudot, era esposa del astrónomo francés Flammarion y profesaba, igual que su marido, ideales librepensadores y espiritistas. Ver CHAUCHAT, A. M, Histoire de la presse en dix portraits. La curieuse et grande figure de Theophastre Renaudot, Sieur de Boissèrie, fondateur du journalisme en France. Prèface de Mme. Cammille Flammarion, née Renaudot, Paris, 1937 y FlamaRION, Camile y SPALIKOWSKI, Edmond, Mortalitè et paix armée, Paris, 1904.

24. La Conciencia Libre. Segunda época, Año II. nº 6, Málaga, 6-I-1906.

25. Ver RAmos, $M^{a}$ Dolores, «La cultura societaria del feminismo librepensador (18951918)», en BuSSY-GENEVOIS, Danièle (dir.), Les espagnoles dans l'Histoire. Une sociabilité démocratique (XIXe-XXe siècle), Saint-Denis, 2002, pp. 103-124; «Radicalismo político, feminismo y modernización. 1889-1920», en GÓMEZ FERRER, Guadalupe; CANO, Gabriela; BARRANCOS, Dora y LAVRIN, Aurora (coords.), Historia de las mujeres en España y América Latina. IV. Del siglo XX a los umbrales del siglo XXI, Madrid, 2006, pp. 31-53; «La República de las librepensadoras (1890-1914): laicismo, emancipismo, anticlericalismo», en RAmOS, M ${ }^{a}$ Dolores (ed.), República y republicanas en España (Monográfico), Ayer, $n^{\circ} 60$ (2005), pp. 45-74; «Hermanas en creencias, hermanas de lucha. Mujeres racionalistas, cultura republicana y sociedad civil en la Restauración», en RAMOS, $\mathrm{M}^{a}$ Dolores (coord.), Laicismo, identidades y cultura política. Mujeres fragmentadas (Monográfico), Arenal. Revista de Historia de las Mujeres, vol. 11, nº 2 (2004), pp. 27-56. 
lado por estas mujeres en el marco de los ideales cívicos universalistas que se consideraban «hijos del 14 de julio», los efectos beneficiosos del gorro frigio, «símbolo de derechos no gozados», y la herencia recibida de las socialistas utópicas, manifestándose todo ello en los discursos y prácticas sociales: mítines, giras propagandísticas, veladas culturales, conmemoraciones, banquetes de promiscuación, inscripciones civiles de nacimientos, matrimonios y defunciones, confección de calendarios laicos, testamentos de renuncia a la fe católica, apertura de escuelas racionalistas, fundación de gabinetes de lectura y movilizaciones por la paz, entre otras iniciativas ${ }^{26}$.

El establecimiento de «hermandades» y pactos solidarios, así como la extensión de unas redes que parecían haber sido trazadas con la escuadra y el compás, según refleja el meticuloso y puntual reparto de tareas, traslados y relevos, surtieron efecto. Muchas mujeres se identificaron con las líderes del librepensamiento tras la lectura individual o colectiva de sus publicaciones periódicas y manifestaron en las páginas de La Luz del Porvenir, Las Dominicales, El Progreso y La Conciencia Libre la emoción que sentían al verlas llevar «la bandera roja del pueblo, que es la bandera de la humanidad culta y progresiva, con más autoridad que los hombres por el hecho de merecer la confianza de las mujeres».

Las lectoras comparaban el perfil político de las dirigentes republicanas con el de «los maestros Nakens y Bonafoux», ensalzando su lenguaje de «acero» en la lucha cuerpo a cuerpo. Lenguaje compatible con la escritura de «arrebatadoras poesías» y la lectura de conmovedores discursos, como acostumbraba a hacer Amalia Domingo Soler, mujer de "palabra serena y tranquila, llena de afanes celestiales». En la prensa del feminismo laicista se podía percibir el carácter pionero de la dramaturga y librepensadora panteísta Rosario de Acuña, cuya trayectoria sirvió de ejemplo a sus compañeras, el celo republicano de Ángeles López de Ayala, presente también en sus libros de texto (Primitivo, Luz, Sol); comparar la «acción realista» de las hermanas Amalia y Ana Carvia con los «tonos dramáticos» de su escritura; seguir los pasos de la militante federal María Marín, «arrebatada» en sus escritos, «verdadera iconoclasta de todas las escuelas» y espíritu independiente, cuyo activismo la llevó a colaborar en numerosos periódicos ${ }^{27}$; conocer los numerosos actos organizados por las maestras republicanas Amparo Lorente y Elena Just, vinculadas a la

26. Las Dominicales del Librepensamiento, 8-II-1900. Cf. SANFELIU, Luz, «Familias republicanas e identidades femeninas en el blasquismo, 1896-1910», en RAMOS, Mª Dolores, Republicanas..., pp. 75-103 y RAmOS, $\mathrm{M}^{\mathrm{a}}$ Dolores, «Hermanas en creencias..., pp. 37-52.

27. La Unión de Jerez, Heraldo de Cádiz, La Conciencia Libre, El Pueblo, El Federal, El Gladiador del Librepensamiento, entre otros. 
Asociación General Femenina y la Sociedad Bien de Obreras, ambas entidades con sede en Valencia; valorar la trayectoria de las profesoras Soledad Areales, expedientada en Córdoba por sus ideales, y Amalia Pérez Congiu, directora de la Escuela Moderna para niñas abierta en Málaga; percibir el pulso librado por la periodista Consuelo Álvarez Pool - «modesta violeta», según se hacía llamar- en las campañas feministas anticlericales de 1906-1907, o condenar los insultos de que fue objeto la escritora $\mathrm{M}^{\mathrm{a}}$ Pilar Cañamaque, tildada de «histérica», «sugestionada» y «confundida» por hacer añicos el ideal doméstico y mantener que «el intelectualismo» de las mujeres no era un sueño ni una quimera; comparar la «altivez oratoria y el temperamento de polemista ardiente» de Belén Sárraga con los tiernos sentimientos que le inspiraba su marido, al que consideraba «alma gemela» a la suya en los años felices de su matrimonio, según reconoció en el libro de poemas Minucias, considerado por los críticos «una pequeña Biblia de amor, catecismo cívico y Evangelio de libertad», un hermoso conjunto de «cantos a la humanidad, inspirados por nobles y elevados ideales ${ }^{28}$.

En fin, en la prensa del feminismo laicista se podía constatar que el núcleo catalán integrado por Palmira de Bruno, María Trulls, Antonia Amat, Julia Aymá, Aurea Amigó, Carmen Piferrer y Francisca Benaigues, entre otras muchas, se había situado en la frontera intimidante que separa el adentro, el mundo reconocible como propio, y el afuera, que sugiere lo extraño, lo impropio, lo que se aleja de la normativa, lo desconocido. Su incansable actividad fue saludada en Inglaterra como un valeroso «hecho de armas» protagonizado por «un pequeño ejército de luchadoras del progreso ${ }^{29}$. El carácter referencial que adquirieron fue subrayado por las lectoras: «Herid sin tregua -escribía una de ellas-; que la posteridad os reserva un lugar en su alma. Mi corazón está a vuestro lado, y a vuestro lado está mi pequeño esfuerzo» ${ }^{30}$. Un talante rupturista que afectaría también a la vida privada de las librepensadoras: mujeres «divorciadas» antes de que el derecho de familia normalizara su situación en el código civil, mujeres solteras por elección y decididas a compartir su existencia, mujeres acogidas en comunidades amplias, como ocurría en la «gran familia espiritista» ${ }^{31}$. Activistas, en suma, que se movilizan, viajan, cambian de residencia y ciudad, incluso de país, dejando una

28. Las Dominicales, 28-II-1902.

29. «¡All right!», La Conciencia Libre, Segunda Época. Año I, nº 1, Málaga, 2-XII-1905.

30. La Conciencia Libre, Segunda Época. Año II, nº 9, Málaga, 27-I-1906.

31. RAmos, $\mathrm{M}^{\mathrm{a}}$ Dolores, «Heterodoxas religiosas, familias espiritistas y apóstolas laicas a finales del siglo XIX: Amalia Domingo Soler y Belén de Sárraga Hernández», Historia Social, n 53 (2005), pp. 65-83, y «La cultura societaria...», p. 114. 
estela de discursos, enseñanzas, asociaciones, periódicos y correspondencia en su empeño de eliminar el conservadurismo y el clericalismo, dos potentes símbolos del siglo que acababa en España. Mujeres doblemente «raras» por ligar su «fortaleza intelectual», su «libertad del pensamiento» y su «impugnación del utilitarismo burgués»-rasgos atribuidos por Rubén Darío a rebeldes, bohemios y vanguardistas en su libro Los raros- a su condición femenina, es decir a la «otredad» que representaban y a la modernidad que adornaba el horizonte del novecientos ${ }^{32}$.

Excepto Amalia Domingo Soler, todas fundieron sus prácticas políticas, sociales y cívicas con los rituales masónicos ${ }^{33}$. Eran arquitectas de la República, feministas anticlericales y obreras de la masonería femenina y mixta. El caso de Domingo Soler es muy significativo, pues compartió numerosas actividades con sus compañeras masonas y con los «hermanos» de los talleres de la rama espiritista española, dirigidos por el venerable Vizconde de Ros, pero rechazaba de plano las «cavilaciones para establecer Consejos, expedir Patentes y Diplomas, formar Delegaciones, otorgar Grados y formular Consignas» ${ }^{34}$. Un mundo de jerarquías y cautelas que se tornaba, tratándose de mujeres, aun más diferenciado y subordinado. Al menos hasta la fundación en 1893 de la Orden Mixta Internacional «El Derecho Humano», impulsada por los reformadores Marie Deraismes y Georges Martin. Este proyecto fue anunciado por la propia Deraismes en la sesión de apertura del Congreso Feminista Internacional celebrado en París el año 1889: «Se prepara una gran revolución, la más grande, la más fecunda que se haya visto, y se hará sin insurrección en la calle, sin barricadas, sin dinamita. Se hace en este momento en las conciencias, se hará pronto en las leyes. Para esto bastará restablecer la ley del orden [natural]: que los dos factores de la humanidad sean igualitarios y no jerárquicos. Este es el precio del desarrollo continuo e indefinido del progreso de la humanidad $»^{35}$. A la revolución masónica anunciada se sumaron, además de la propia Deraismes, Marie Martin, Marie Bonnevial y Marguerite Martin, vinculadas al Journal des Femmes, La Fronde y la Ligue du Droit des Fe-

32. DARÍO, Rubén, Los raros, Barcelona, 1905.

33. LACALZADA, M ${ }^{a}$ José, «Laicismo, derechos humanos y derechos femeninos en la masonería», en RAMOS, $\mathrm{M}^{a}$ Dolores (coord.), Laicismo, identidades..., pp. 5-26 y Mujeres en masonería. Antecedentes históricos entre las luces y las sombras, Barcelona, 2006; ORTíz AlBEAR, Natividad, Las mujeres en la masonería, Málaga, 2005 y SÁNCHEZ FerRé, Pere, La maçoneria en la societat catalana del segle XX, Barcelona, 1993, pp. 25-30

34. RAMOS, $\mathrm{M}^{a}$ Dolores, «Heterodoxias religiosas...», p. 83.

35. LacalzadA, M José, «Laicismo...», p. 22 y El cimiento mixto. El Derecho Humano en España, Madrid, 2007. 
mmes, que llegaron a ser Grandes Maestras de la Orden ${ }^{36}$. También formaron parte de «El Derecho Humano» la sufragista y teósofa inglesa Annie Besant, la científica francesa Clemence Royer, la eugenista francesa Nelly Roussell, la pedagoga belga Isabelle Gatti de Gamond, la médica portuguesa Adelaida Cabete, la médica y sufragista uruguaya Paulina Luisi, la propagandista española Belén de Sárraga y otras muchas que contribuyeron a forjar en los talleres un «feminismo humano, humanista y pacifista».

Este sustrato impulsó a las iniciadas a vincular el «bien común» y el «bien de las mujeres» en las logias y los plurales espacios de la vida profana. La búsqueda de la paz se hallaba enraizada con la armonía social, la felicidad de los pueblos y el ideal de perfectibilidad que debían adornar «la construcción del Templo de la Humanidad» o la «Jerusalén Celeste en la Tierra». En el segundo caso los movimientos sociales que pretendían transformar de manera radical la realidad se solapaban con las miradas que intuían una dimensión oculta de la misma y las capacidades inexploradas del espíritu humano presentes en la tradición hermética, espiritual y ocultista: desde el misticismo y el milenarismo a las formulaciones del socialismo utópico, el espiritismo y la teosofía ${ }^{37}$.

\section{El movimiento feminista y la Conferencia de Paz de La Haya (1899)}

«Hagamos, sí, labor de paz sin tregua ni descanso. La tarea es larga; no es de un día, ni de un año... Si hoy la empezamos en la cuna, mañana la coronarán los pueblos uniéndose en una aspiración común a despecho de fronteras».

Belén de Sárraga

El marco histórico e ideológico facilitó el desarrollo de la cultura de la paz en el cruce de los siglos XIX-XX. Bastará recordar dos iniciativas simultáneas: la campaña antimilitarista desarrollada en España con motivo de la guerra de Cuba y la celebración del Congreso Internacional del Librepensamiento organizado en Bruselas en 1895, donde se discutió sobre la necesidad de abolir o flexibilizar las fronteras y difundir las bondades de una utópica «Patria Universal». El reclutamiento y envío a tierras antillanas de más de cien mil

36. Marie Deraismes alcanzó la cúpula de la organización en 1893-1894; Marie Georges Martin en 1903-1914; Marie Bonnevial en 1914-1918 y Marguerite Martin en 19471954. Ver RABAUT, Jean, Marguerite Durand (1864-1936). «La Fronde» féministe ou «Le Temps» au jupons. Préface de Madeleine Rebérioux, Paris, 1996, pp. 43-44 y ss.

37. Ver Delgado, Manuel, Prólogo a Gerard Horta, De la mistica a les barricades. Introducció a l'espiritisme català del XIX dins el context ocultista europeu, Barcelona, 2001, p. 7 y el artículo de la profesora Gloria Espigado en este Dossier. 
soldados españoles avivaría en nuestro país estas iniciativas, mientras se enconaba la lucha entre tradición y revolución, se recrudecía la confrontación clerical/anticlerical, representada en el drama de Pérez Galdós Electra, y crecía la dialéctica acción terrorista-represión policial en Barcelona, donde las redadas indiscriminadas y las torturas infringidas en 1896 a los presos en el «castillo maldito» de Montjuich, entre los que se encontraban los librepensadores anarquistas Teresa Claramunt y Juan Montseny ${ }^{38}$, inspiraron a Belén de Sárraga la composición que sigue:

«Masa gigante que elevó el pasado/como él, triste, feroz, tétrica y negra/ Mole atrevida que pregona infamia/y a España en tintes de baldón sombrea/castillo maldecido por las gentes/miserable y odiada fortaleza/ que, en antro de verdugos convertida/la execración junto a su nombre ostenta/Vedla; elevada sobre enhiesta cumbre/Recortada en las nubes su silueta/Más alta aún que de las fábricas/las parduscas y esbeltas chimeneas/Parece, cuando el sol allá en la tarde/Rojo al morir, de rojo la llama/Espíritu fatal del retroceso/que el paso de la industria airado acecha/,y ante el trabajo, que a sus pies camina/medita el crimen y con sangre sueña.... $»^{39}$.

El texto responde a la práctica cultural de utilizar la poesía y la prosa poética en libros, folletos y periódicos. En los años noventa la prensa de izquierdas se llenó de colaboraciones que clamaban contra la tortura, la pena de muerte, siempre «destructora en sí misma», y el falso sentido de la justicia, «que debía aspirar, ante todo, a reparar el daño causado $»^{40}$. En uno de sus artículos Ángeles López de Ayala llegó a poner en tela de juicio la ley de asociaciones y el sufragio universal masculino. Más aún: planteó la necesidad de que la Monarquía diera paso a la República, advirtiendo que ésta, lejos de ser un fin en sí misma, debía abrir el camino a la Democracia. La escritora dudaba de que «los oprimidos hubieran conquistado su libertad, y mucho menos sus derechos, ya que aquélla había quedado reducida a la triste situación de debilidad que padecen el inválido, el moribundo y el infante» ${ }^{41}$. Por este motivo las sociedades racionalistas, feministas, anticlericales, masónicas, espiritistas, filosóficas y científicas debían exigir «pan y trabajo para las clases trabajadoras», reivindicar la «paz universal» y poner fin a la discriminación sexual, considerada un elemento desestabilizador de la moral natural y de las relaciones sociales de género y clase ${ }^{42}$. En gran medida, Ángeles López de Ayala seguirá

38. Vicente Villanueva, Laura, Teresa Claramunt. Pionera del feminismo obrerista anarquista, Madrid, 2006.

39. SÁrraga de Ferrero, Belén, Minucias, Málaga, 1901, p. 19.

40. La Tramontana, 7-VIII-1891.

41. Las Dominicales del Librepensamiento, 28-IX-1894.

42. Las Dominicales del Librepensamiento, 17-V-1895. 
las propuestas del maestro Pi y Margall, que había exigido en el Programa del Partido Federal de 1894 un "poder que rija las relaciones internacionales», la solución de las discordias por el arbitraje y «la sustitución de las armas por la razón y el derecho ${ }^{43}$. Por su parte, los institucionistas Rafael Altamira y Rafael $\mathrm{M}^{a}$ de Labra, además de insistir en parecidos aspectos, se inclinaron por otorgar un presupuesto moral al derecho internacional y el movimiento pacifista ${ }^{44}$.

La inmediata escenificación de los argumentos de López de Ayala tuvo lugar durante la guerra hispano-norteamericana. Las manifestaciones pacifistas contrarias al servicio militar de los pobres y al conflicto bélico confluyeron con las protestas por las condiciones en que llegaban los soldados de los frentes y los motines por la escasez de alimentos desarrollados en Valencia, Zaragoza, Madrid, Barcelona, Córdoba, Linares, Vigo, Toledo y Logroño. Las «hijas del pueblo» se rebelaron y actuaron de acuerdo con sus sentimientos maternos, exigiendo a los poderes facilidades para cumplir los roles femeninos. Conciencia femenina y conciencia pacifista llevaron a las mujeres a participar en numerosas acciones colectivas. El poema «Ante la repatriación» refleja ambas formas de conciencia:

«Pueblan los aires fúnebres acentos/desolados lamentos/se oyen doquiere el pensamiento llega/y lleno de amargura/cubierto de tristura/en mar de llanto el corazón navega .../iEllas, ellas solas han aguardado/al pobre repatriado/ calor ofrecen en su hogar desierto/y en labio no esquivo /besan al hombre vivo/recordando tal vez al hijo muerto/ellas tan solo, sí, mientras inerte/España ante la muerte/de quien luchó con el valor entero/solo tiene, arrogante/la limosna insultante/que convierte al patriota en pordiosero» ${ }^{45}$.

Luz Sanfeliu ha señalado que en los medios republicanos no sólo las madres sino todas las mujeres adquirían significación por el hecho de saber reconocer y sumarse a la protesta contra las inconcretas situaciones sociales relacionadas con «lo nimio y absurdo» ${ }^{46}$. Es cierto que en la coyuntura del 98 las mujeres salieron a las calles de forma espontánea para defender el derecho a la vida de sus hijos, obligados por la falta de recursos a ir a la guerra. Pero al hacerlo no sólo irrumpieron en la esfera pública sino que elaboraron su propia "política» y priorizaron la paz como un valor supremo lleno de contenido ético. Algo que muy difícilmente podían apreciar las autoridades. En 1896

43. Pi y Margall, Francisco, Programa del Partido Federal del 22 de junio de 1894, San Feliu de Guixols, 1894.

44. RAMOS, Vicente, Rafael Altamira, Madrid, 1968.

45. SÁRraga de Ferrero, Belén, Minucias..., pp. 36-37.

46. SAnfeliu, Luz, Republicanas..., pp. 98-101. 
cinco defensoras de la paz fueron detenidas y conducidas al Asilo-Cárcel de Valencia, donde permanecieron varios meses, quedando pendientes de juicio hasta $1897^{47}$. Una de ellas era la propagandista republicana Belén de Sárraga, embarazada de varios meses de su hija Libertad. Aunque las movilizaciones femeninas tenían mucho que ver con la asignación social de las tareas de cuidado adjudicadas a las mujeres y la experiencia diferencial de éstas como madres biológicas y sociales, la reivindicación de la paz abrió espacios cívicos y constituyó una práctica transgresora muy alejada de las tradicionales pautas de socialización ejercidas por las mujeres ${ }^{48}$.

La novela antimilitarista Abajo las armas, publicada en $1889^{49}$, de la que se vendieron miles de ejemplares en diferentes idiomas, catapultó a su autora, la aristócrata Bertha von Suttner, a la cima del movimiento pacifista. La narración, en gran medida autobiográfica, aborda la historia de una mujer que pierde a su primer marido en la batalla de Solferino y al segundo en un atentado perpetrado durante el conflicto franco-prusiano. La descripción de las realidades del frente, los problemas surgidos en la retaguardia, la condena de la ideología militarista, la asociación del heroísmo con la virilidad y la crítica a la Iglesia por su respaldo al belicismo, constituyen la trama ideológica de la novela. Suttner se sintió obligada a explicar la relación que existía entre el texto y su activismo pacifista: la novela no fue la causa de su compromiso sino que «ocurrió justamente lo contrario... $»^{50}$. La obtención del Premio Nobel de la Paz en diciembre de 1905 selló su militancia antimilitarista y feminista, que ya no abandonaría durante el resto de su vida:

«Alguna gente piensa que las mujeres son hostiles a la guerra por naturaleza. Están en un error. Sólo las mujeres progresistas, aquellas que han sido capaces de educarse a sí mismas en una conciencia social, que han tenido la fuerza de no dejarse fascinar por instituciones con centenares de años, encuentran también la energía para oponerse a ellas» ${ }^{51}$.

47. Ibidem, p. 99

48. NASH, Mary y TAVERA, Susana, Experiencias desiguales. Conflictos sociales y respuestas colectivas (siglo XIX), Madrid, 1994, p. 147.

49. SutTNER, Bertha von, Abajo las armas, Barcelona, 1906. Le siguieron otras ediciones en Sopena, 1936, [1948], 1958, 1961 y Mateu, 1964.

50. PORQUERES, Bea, Tres creadores contra les guerres..., pp. 20-21.

51. SUTTNER, Bertha von, Discurso pronunciado en el Movimiento de Mujeres Alemanas por la Paz, 1914. Ver Magallón Portoles, Carmen, «De la reclamación de la paz...», p. 15; SutTner, Bertha von, Souvenirs de guerre, Paris, 1904 y MÜller, Arthur; SutTner, Bertha von, Ligue pacifiste à l'usage de la jeuneusse. Un conseiller pour parents et éducateurs, Renaix, 1901. 
De acuerdo con ese perfil, las librepensadoras españolas respaldaron la organización de la Primera Conferencia Internacional de la Paz celebrada en La Haya en $1899^{52}$, siguiendo los pasos del movimiento feminista internacional, que había convocado asambleas y manifestaciones simultáneas el 15 de mayo. Las redes nacionales y transnacionales jugaron un importante papel a la hora de poner de acuerdo a las activistas inglesas, belgas, alemanas, francesas, rusas, polacas, italianas, portuguesas y españolas. El espontaneísmo había quedado atrás, siendo sustituido por acciones coordinadas de acuerdo con unos objetivos pactados de antemano y unas tácticas comunes. A la tradicional «ética del cuidado» se sumaban ahora las demandas de unas ciudadanas sensibilizadas por «el problema de las guerras» desde el punto de vista moral, político y económico.

La movilización fue promovida por mujeres republicanas, liberales y progresistas, destacando entre ellas Bertha von Suttner y Margarethe Lenore Selenka (1860-1922), paleontóloga y profesora de la Universidad de Munich -integrante del grupo de científicos que descubrió el «Hombre de Java»-, convencida defensora de la relación que existía entre la discriminación de las mujeres y las diferentes formas de violencia política y social ${ }^{53}$. Su pacifismo giraba en torno a dos ejes: por una parte, el fortalecimiento del derecho internacional y la creación de tribunales de arbitraje; por otra la necesidad de que las mujeres abandonaran su pasividad y se involucraran en la esfera política. El objetivo era que tomaran la palabra y discutieran sobre la paz, «asunto de primer orden»: un «bien imprescindible para el progreso de la humanidad ${ }^{54}$. En ese sentido, correspondería a las mujeres «más conscientes» erradicar la ignorancia, el escepticismo o la indiferencia que mostraban las demás, intercambiando con ellas «mensajes de paz y simpatía». La fórmula elegida fue la celebración de asambleas nacionales promovidas en cada país por grupos feministas. Se pretendía que las reuniones fueran amplias y que en ellas participaran mujeres de diferente procedencia social.

Es significativo que los trabajos publicados sobre la Primera Conferencia de La Haya ignoren estas manifestaciones, pues están planteados desde la óptica de la política exterior, las relaciones internacionales y la diplomacia ${ }^{55}$.

52. Las Dominicales del Librepensamiento, 18-V-1899.

53. KATZEL, Ute, «A radical women's rights and peace activist: Margarethe Lenore Selenka, initiator of the first worldwide women's peace demonstration in 1899», Journal of Women's History, Vol. 13:3 (Fall 2001), pp. 46-67.

54. SelEnKA, Lenore, La manifestation internationale des femmes pour la Conférence de la Paix, du 15 mai 1899, Munich, 1900.

55. Ver, entre otros, LÓPEZ CORDÓN, $M^{a}$ Victoria, «España en las Conferencias de La Haya de 1899 y 1907», Revista de Estudios Internacionales, vol. 3, nº 7 (1982), pp. 703-756. 
Convocada en un clima de escepticismo, desconfianza y sorpresa tanto por el origen de la propuesta -el gobierno del zar Nicolás II de Rusia- como por la tensión internacional creada por la guerra hispano-norteamericana y el conflicto anglo-francés en Sudán, sólo recibió en principio el apoyo incondicional de Suiza y Holanda. En España obtuvo el rechazo de los socialistas, que siguieron las directrices de la II Internacional, los republicanos federales y los anarquistas, que consideraron la reunión una farsa.

La Conferencia tuvo lugar entre el 18 de mayo y el 29 de julio de 1899 , participando en ella Estados Unidos, México. China, Japón, Siam y Persia, además de veinte países europeos, entre los que se encontraba España, cuyo aislamiento se hizo evidente desde el principio al quedar relegada entre las naciones de segundo y tercer orden ${ }^{56}$. Las grandes potencias aparcaron en seguida la cuestión del desarme y sólo propusieron la utilización de medidas de arbitraje en los asuntos que no comprometieran «el honor ni los intereses vitales». En el acta final se recogieron tres acuerdos: el compromiso de encontrar soluciones pacíficas a las diferencias entre las naciones; la adaptación de la guerra marítima a la Convención de Ginebra de 1864, que obligaba a respetar los buques hospitales y la inmunidad del personal sanitario y las sociedades de socorro como la Cruz Roja; y la aprobación de un Reglamento con el que se trató de disminuir en lo posible los desastres y efectos colaterales de la guerra terrestre. Además se firmaron tres declaraciones para prohibir el uso de algunas armas, se constituyó un Tribunal de arbitraje, precedente de la futura Sociedad de Naciones y del Tribunal Internacional de Justicia, y se adoptó por unanimidad la siguiente resolución: «La Conferencia estima que la limitación de cargas militares que pesan actualmente sobre el mundo es deseable en gran manera para el crecimiento del bienestar material y moral de la humanidad». España suscribió todos los acuerdos ${ }^{57}$.

El escepticismo generalizado que rodeó la preparación de la Conferencia de La Haya contrastó con el interés que mostró la prensa librepensadora por difundir el proyecto. Las Dominicales destacó el movimiento emprendido por

JiMÉNEZ PiERnAS, Carlos Bartolomé, «El papel de España en la Conferencia de La Haya de 1899», Revista Española de Derecho Internacional, vol. 51, no 2 (1999), pp. 775-781 y Eymar, Carlos, «Primer Centenario de la Conferencia de Paz de La Haya», Análisis, no 4 (23-XII-1999), pp. 1-7.

56. La delegación española no contó con juristas. Estuvo formada por Carlos O`Donell, duque de Tetuán, senador vitalicio y ex ministro de Estado, Wenceslao Ramírez de Villa-Urrutia y Arturo Baguer, ministros plenipotenciarios en Bruselas y los Países Bajos. LóPEZ Cordón, $\mathrm{M}^{a}$ Victoria, «España en las Conferencias...», p. 715.

57. EYMAR, Carlos, «Primer Centenario...», pp. 5-6 y LÓPEZ CORDÓN, M ${ }^{a}$ Victoria, «España en las Conferencias...», pp. 713 y 716. 
«las mujeres de los países civilizados (...) acordando realizar un acto colectivo a favor de la paz» ${ }^{58}$.

La Asamblea de Mujeres españolas se celebraría en Valencia, ciudad donde había surgido dos años antes la Asociación General Femenina impulsada por Ana Carvia y Belén de Sárraga. El acto contó con el aval de casi un centenar de librepensadoras, republicanas, escritoras, obreras, artesanas, maestras laicas y afiliadas a la masonería ${ }^{59}$. Mujeres prefiguradas en el sistema de representaciones del blasquismo como el arquetipo de la «valencianeta, de ojos vivos y mirada ardiente, con el gorro frigio republicano ${ }^{60}$. Según Ramir Reig, la ciudad del Turia contaba a finales de siglo con un fuerte dinamismo sociocultural, reforzado por la pujanza del republicanismo y la presencia de «un pueblo entusiasta y respetuoso...». Los blasquistas se preguntaban si podía haber un lugar mejor para consolidar la cultura de la paz, ya que sus casinos políticos, logias masónicas, asociaciones femeninas, ateneos populares y círculos filosóficos, avalados por un numeroso grupo de oradores y oradoras, habían logrado que Valencia se transformara en la «Atenas del Mediterráneo ${ }^{61}$. Pero la elección se debió a otras razones. Madrid carecía de una entidad consolidada de mujeres librepensadoras. Barcelona comenzaba a rehacer las redes del feminismo laicista tras una etapa de atonía. Ángeles López de Ayala, dirigente de la Sociedad Progresiva Femenina, radicada en Barcelona, estaba a punto de protagonizar el relevo en la dirección del proyecto que durante los dos últimos años habían liderado las librepensadoras valencianas, pero el hecho aún no se había producido. Por otra parte, Belén de Sárraga contaba con numerosos contactos internacionales, como veremos a continuación.

Margarethe Lenore Selenka, una de las organizadoras de la movilización, formaba parte, junto con una nutrida representación de krausistas -Adolfo Posada entre ellos-, librepensadores y feministas, del amplio grupo de promotores de la Revue de Sociale Morale, surgida en Ginebra el primer trimestre de 1899 con el objetivo de regular «las relaciones morales y sociales entre los sexos», conferir a mujeres y hombres derechos y deberes recíprocos, prerrogativas en la familia y normas para sus relaciones. Formaban parte de ese grupo Belén de Sárraga, Elizabeth Blackwell, Josephine Butler, María Martin, Helène de Gingins, Helena de Mulinen, Emma Pyczynska, Marie Popelin, junto con

58. Las Dominicales del Librepensamiento, 18-V-1899.

59. Unas cien mujeres, según el informe de Adolfo Posada en la Revue de Morale Sociale, $\mathrm{n}^{\circ} 4$ (octobre-décembre 1899), p. 512. Unas setenta, según la apreciación de REIG, Ramir, Obrers i ciutadans. Blasquisme i moviment obrer, Valencia, 1982, p. 158.

60. El Pueblo, 20-I-1900.

61. Cit. en ReIG, Ramir, Obrers i ciutadans..., p. 360. 
otras publicistas, profesoras, médicas, escritoras, periodistas y abogadas europeas. Estas activistas compartían la idea de que la igualdad de derecho y de hecho entre mujeres y hombres aseguraría «en gran medida la felicidad o la desgracia de los individuos, la prosperidad o la decadencia de las naciones y el futuro de la especie humana $»^{62}$. Sárraga desgranaría su discurso pacifista, igual que Amalia Domingo Soler, Amalia Carvia, Ángeles López de Ayala y el resto de las librepensadoras, en diferentes ocasiones:

« ¿Es delito no amar las fronteras? Me declaro delincuente. ¿Es crimen odiar las armas de destrucción? Soy criminal... la naturaleza, madre y creadora, es la única que posee el derecho de vida y muerte; el hombre, incapaz de crear vida, no tiene el derecho de destruirla $»^{63}$.

La propagandista y escritora española fue requerida por sus compañeras de la Revue de Morale Sociale para que liderara en nuestro país la campaña pacifista. La polaca Zofía Daszynska le dirigió una carta en estos términos:

«iSalud, mujeres reunidas en nombre del Congreso y de la Paz Universal! Compartiendo vuestra acción, nosotras deseamos también el advenimiento de la fraternidad entre los pueblos, sin poder aprobar el statu quo que ultraja la unidad y la independencia de Polonia. ¡Viva la paz universal entre naciones libres y bajo un régimen de justicia! ${ }^{64}$.

Pero la etapa valenciana de Belén de Sárraga estaba llegando a su fin. En abril de 1899, mientras realizaba una gira en compañía de los republicanos-socialistas del grupo Germinal y trataba de reorganizar la Federación malagueña de sociedades de resistencia ${ }^{65}$, entidad obrera y librepensadora que había puesto en pie con Emilio Ferrero y algunos republicanos andaluces en 1897, la presidencia de la Asociación General Femenina pasó a ser ocupada por la maestra racionalista Amparo Lorente. Es posible que las librepensadoras valencianas buscaran vías más autónomas de acción, al margen del carisma «belenista», a la hora de relacionarse con otros grupos feministas igualmente inclinados hacia el laicismo y la liberación de las mujeres, pero la representación en las redes nacionales y transnacionales la seguiría ostentando Sárraga.

La Asamblea de Mujeres por la Paz fue presidida por Julia Álvarez, amiga personal de Amalia Carvia. Según El Mercantil Valenciano -muy escéptico respecto a los posibles resultados de la Conferencia de La Haya-, concurrieron al acto mujeres de todas las clases sociales. En la sala se apreciaban elegantes sombreros, capas, abrigos, mantillas y modestas pañoletas. Algunas mujeres

62. Revue de Morale Sociale, $\mathrm{n}^{\circ} 1$, janvier-mars, 1899, p. 1.

63. La Conciencia Libre, Segunda Época. Año II, nº 9, Málaga, 27-I-1906.

64. Las Dominicales del Librepensamiento, 18-V-1899.

65. El Mercantil Valenciano, 21-IV-1899. 
concurrían a una asamblea de estas características por vez primera. Adolfo Posada, uno de los pocos estudiosos españoles del feminismo europeo, comentó en la Revue de Morale Sociale:

«On avait l'impression d'assister à la manifestation d'un sentiment qui ne s'etait pas encore fait jour jusqu'ici parmi les femmes, soit par crainte de se faire voir en public, soit par respect pour les coutumes du pays» ${ }^{66}$

Julia Álvarez explicó a las asambleístas la necesidad de que las mujeres asumieran la defensa de la paz:

«No puedo aceptar (...) como un hecho lógico (...) que los hombres maten por el afán de matarse y hasta sin saber por qué se matan. No pueden, pues, llamarse con justicia naciones cultas y civilizadas las que proclaman la guerra como derecho» ${ }^{67}$.

La presidenta resaltó la conveniencia de establecer mecanismos de arbitraje para resolver las diferencias entre las naciones y aseguró que las mujeres habían contribuido a desarrollar la idea de la paz. Tras la lectura de las adhesiones nacionales e internacionales se leyó el documento Resolución de las mujeres de España para la Conferencia de la Paz, redactado por Belén de Sárraga y Carmen Ferrero, que se remitiría al comité femenino de La Haya:

«Nosotras, mujeres reunidas en la Asamblea, declaramos unánime y simultáneamente con las mujeres de los demás países del mundo civilizado, que saludamos con regocijo la inauguración de la Conferencia de La Haya encargada de buscar soluciones a una de las cuestiones más importantes de la sociedad moderna: la de sustituir en las relaciones internacionales el régimen de la fuerza bruta por el de los principios de la razón y la justicia. Nosotras enviamos a la Conferencia, con nuestro saludo de simpatía, la expresión de nuestra confianza en que los gobiernos congregados por primera vez para una empresa tan levantada y tan estrechamente unida a los intereses más esenciales de sus naciones respectivas, no dejarán de encontrar un camino -ya allanado por el desenvolvimiento de la historia moderna- que acorte la distancia que nos separa de ese gran fin que lleva consigo la liberación de la humanidad de los terribles males de la guerra y del peso, cada día mayor y más insoportable, de la paz armada ${ }^{68}$.

En 1901 Amalia Carvia recordaba con orgullo el acontecimiento: «A Valencia le cupo la honra de levantar la voz en nombre de las mujeres españolas en años anteriores ${ }^{69}$. Efectivamente, hasta la encrucijada de la Primera Guerra

66. Informe de Adolfo Posada. Revue de Morale Sociale, $\mathrm{n}^{\circ}$ 4, octobre-décembre 1899, p. 512.

67. El Mercantil Valenciano, 18-IV-1899.

68. Las Dominicales del Librepensamiento, 18-V-1899.

69. El Pueblo, 16-V-1901. 
Mundial las republicanas españolas se vincularon a las corrientes ideológicas racionalistas, liberales en el más amplio sentido de la palabra, que postulaban el progreso de la humanidad, la fraternidad, la importancia del cosmopolitismo frente a los nacionalismos, el laicismo, la libertad de conciencia, la noción de autoconstrucción del individuo y la perfectibilidad humana: «Deber, y deber incontrovertible en todo organismo francmasónico -resaltó Elena Just en 1907- es sostener enhiesta siempre y en todo caso la bandera de la Paz, tanto en empresas grandes, internacionales, como en las denominadas civiles, por producirse en el interior de un país» ${ }^{70}$.

Era sin duda una apuesta por el antimilitarismo y el desarme; era también una apuesta feminista. Paulatinamente, las mujeres habían construido un espacio propio en el marco de las «familias» republicanas, habían logrado reformular aspectos cruciales relacionados con la paz, la ciudadanía y la feminidad, otorgando nuevos significados a las culturas políticas de izquierdas y a sus identidades. Sabían que la consecución de una paz duradera precisaba un brazo femenino que combatiera la guerra y el militarismo en el hogar, la escuela y la sociedad. Sólo así se inscribiría la no violencia en el espíritu del siglo XX.

Las tejedoras de paz continuarían su trabajo. Es preciso recordar que la consigna «guerra a la guerra», difundida por las feministas que apoyaron las Conferencias de Paz de La Haya de 1899 y 1097, y aprobada por las delegadas de las Conferencias de la Internacional de Mujeres Socialistas de Stuttgart (1907), Copenhague (1910) y Berna (1915), constituyeron el precedente de la Conferencia de Zimmmerwald, sin duda la mayor manifestación del socialismo internacionalista antibélico durante la Primera Guerra Mundial ${ }^{71}$. En una línea similar se sitúa la creación de la Liga Femenina Española por la Paz en 1930, de la que formaron parte Clara Campoamor e Isabel Oyarzábal, y la fundación del movimiento pacifista, antifascista y feminista AmsterdamPleyel, enmarcado en el ámbito «frentista» de la Internacional durante esos años. Consecuencia de ese movimiento fue la Conferencia Mundial de Mujeres contra la Guerra y el Fascismo celebrada en París en 1934, que contó con la participaron de las dirigentes belgas Lucia de Brouckère e Isabelle Blume ${ }^{72}$

70. LACAlZADA, Ma José, Mujeres en masonería..., p. 202.

71. Rosal, Amaro del, Historia de la UGT de España. I, Barcelona, 1977 y ForCADELL, Carlos, Parlamentarismo y bolchevización. El movimiento obrero español. 1914-1918, Barcelona, 1978.

72. Prezeau, J., «Le Mouvement Amsterdam-Pleyel (1932-1934). Un champs d'essai du Front Unique», Cahiers d'Histoire de l'IRN (Paris), nº 18 (1984), pp. 85-99 y GOTOVICH, José, Isabelle Blume. Entretiens, Bruxelles, 1996. 
y una representación de la Agrupación de Mujeres Antifascistas de España (AMA), que adoptaron el discurso de la maternidad como fuente de derechos, reactivándolo en el marco de la Unión de Mujeres Antifascistas Españolas (UMAE) $^{73}$, fundada en Francia en 1946. Estas iniciativas revelan la existencia de un compromiso pacifista continuado y con proyección internacional en las filas feministas.

73. Moreno, Mónica, «Republicanas y República en la Guerra civil», en RAmOS, Ma Dolores (ed.), Republicanas..., pp. 168-172 y YUSTA, Mercedes, «The mobilization of the women in exile: the case of the Union de Mujeres Antifascistas Españolas in France (1944-1950)», Journal of Spanish Cultural Studies, nº 6 (2005), pp. 43-58. 